\title{
Fifty nanometer lines patterned into silica using water developable chitosan bioresist and electron beam lithography
}

Mathieu Caillau, Pierre Crémillieu, Emmanuelle Laurenceau, Yann Chevolot, Jean-Louis Leclercq, Sergeï Alekseev, Céline Chevalier, and Thierry Delair

Citation: Journal of Vacuum Science \& Technology B 35, 06GE01 (2017); doi: 10.1116/1.4996870

View online: https://doi.org/10.1116/1.4996870

View Table of Contents: https://avs.scitation.org/toc/jvb/35/6

Published by the American Vacuum Society

\section{ARTICLES YOU MAY BE INTERESTED IN}

Adjustable sidewall slopes by electron-beam exposure layout

Journal of Vacuum Science \& Technology B 35, 06 G501 (2017); https://doi.org/10.1116/1.4993724

Crosslinkable photoacid generators for ultrahigh loading in epoxide functionalized molecular resists Journal of Vacuum Science \& Technology B 35, 06GE02 (2017); https://doi.org/10.1116/1.4991894

Effects of stochastic exposure on critical dimension in electron-beam lithography Journal of Vacuum Science \& Technology B 35, 06 G503 (2017); https://doi.org/10.1116/1.4995445

Study of shot noise in photoresists for extreme ultraviolet lithography through comparative analysis of line edge roughness in electron beam and extreme ultraviolet lithography

Journal of Vacuum Science \& Technology B 35, 061602 (2017); https://doi.org/10.1116/1.4991054

Lithographic performance of ZEP520A and mr-PosEBR resists exposed by electron beam and extreme ultraviolet lithography

Journal of Vacuum Science \& Technology B 35, 061603 (2017); https://doi.org/10.1116/1.5003476

Improvement of silicon waveguide transmission by advanced e-beam lithography data fracturing strategies

Journal of Vacuum Science \& Technology B 35, 06G504 (2017); https://doi.org/10.1116/1.4991900

\section{AVS Quantum Science}




\title{
Fifty nanometer lines patterned into silica using water developable chitosan bioresist and electron beam lithography
}

\author{
Mathieu Caillau, Pierre Crémillieu, Emmanuelle Laurenceau, Yann Chevolot, ${ }^{\text {a) }}$ \\ and Jean-Louis Leclercq ${ }^{\text {b) }}$ \\ Université de Lyon, Institut des Nanotechnologies de Lyon INL - UMR 5270 CNRS, Ecole Centrale de Lyon, \\ Ecully, F-69134, France \\ Sergeï Alekseev \\ Department of Chemistry, Kiev National Taras Schevchenko University, Volodymyrska St, 60, UA-01601 Kiev, \\ Ukraine
}

\section{Céline Chevalier}

Université de Lyon, Institut des Nanotechnologies de Lyon INL - UMR 5270 CNRS, INSA Lyon, Villeurbanne 69621, France

\section{Thierry Delair}

Université de Lyon, IMP/Polytech, UMR 5223 CNRS, Villeurbanne, F-69622, France

(Received 19 July 2017; accepted 12 October 2017; published 30 October 2017)

\begin{abstract}
Current chemicals used in electron beam (e-beam) lithography generate safety and waste management issues. To replace them, chitosan, a natural and abundant polymer soluble in water based solutions, was assessed as a positive and water developable resist for a two-layer e-beam lithography and as a mask for transfer by etching in silica. Fifty nanometer line patterns were successfully obtained in a chitosan film by e-beam lithography at doses between 160 and $300 \mu \mathrm{C} \mathrm{cm}^{-2}$, then, transferred into a silica layer by $\mathrm{CHF}_{3}$ plasma reactive ion etching with respect of the feature dimensions. Published by the AVS. https://doi.org/10.1116/1.4996870
\end{abstract}

\section{INTRODUCTION}

Today, using green technology has become imperative in most competitive industrial domains. It is particularly the case in the semiconductors industry since the International Technology Roadmap for Semiconductors ${ }^{1}$ did such recommendation in 2011. It is also of prime importance in order to anticipate future regulations, in particular, in Europe registration, evaluation, authorization and restriction of chemicals and in the United States the Pollution Act. Herein, we focus on lithography techniques for which the top surface of a substrate is coated with a resist layer (generally a polymer). This layer is then irradiated with UV light, electron beam (e-beam), or ion beam and developed in a specific solution (developer) in order to generate micron or nanoscale features. Generally, it does necessitate oil derived products such as resists and solvents. Furthermore, developers can be hazardous. Today, the tetramethylammonium hydroxide is the developer that is most used in the industry of the semiconductor; it is toxic and a lethal product for the experimentator. For e-beam lithography, poly(methyl methacrylate) (PMMA) has been widely used as resist since $1968 .^{2}$ It is commercially available in anisole ${ }^{3}$ and developable in a mix of methyl isobutylketone and isopropanol (1:3). ${ }^{4}$ Although PMMA is not hazardous, the syntheses of its methyl methacrylate monomer, its solvent, and its developers require toxic, irritating, lethal, corrosive, and highly flammable chemicals. ${ }^{5-7}$ Consequently, it generates safety, waste management and related costs issues. Nowadays, researchers are looking for alternative chemicals that open the era for a safer and more ecofriendly lithography.

\footnotetext{
a)Electronic mail: Yann.chevolot@ec-lyon.fr

b) Electronic mail: Jean-louis.leclercq@ec-lyon.fr
}

For a few years, biosourced polymers derived from biomass, which are nontoxic, renewable, and biodegradable natural materials, have been studied for water-developable high resolution lithography and have demonstrated their potential on commonly used pattern transfer techniques. ${ }^{8-14}$

Through these studies, it was demonstrated that "green" e-beam lithography can be carried out in an organic-free process with high resolution. Kim et al. ${ }^{11}$ have produced $30 \mathrm{~nm}$ holes spaced of $100 \mathrm{~nm}$ with silk as a positive tone resist but did not transfer the features into the sublaying substrate. The solubility of silk can also be locally modified, thanks to its amorphous to beta sheet thermal transition using a laser. ${ }^{15}$ Takei et al. ${ }^{10}$ have obtained $50 \mathrm{~nm}$ lines spaced of $450 \mathrm{~nm}$ with saccharide based negative tone resist material. Transfer of the features into the subjacent layer by $\mathrm{CF}_{4}$ plasma etching was then realized. ${ }^{8-10,16}$ However, due to the low selectivity of their saccharide layer to etching conditions, they did use a trilayer stack process: (1) saccharide based e-beam resist $(200 \mathrm{~nm}),(2)$ a hard mask silicone-based polymer $(50 \mathrm{~nm})$, and (3) a thick polymer based etching transfer layer $(800 \mathrm{~nm})$. Although the process could be completely done in water, the polymers for the two last layers had to be synthesized. In addition, the saccharide based resist must be functionalized with acryloyl groups in order to be electrosensitive and to crosslink under an e-beam. These syntheses involved chemical synthetic reactions and the use of organic compounds and solvents.

In this work, we propose to use chitosan as positive water developable resist for e-beam lithography and mask for transfer by etching. The resulting features are transferred into the silicon substrate by etching using a classical two-layer process (resist $>$ silica hard mask $>$ silicon). Chitosan is a natural polysaccharide present in the cell wall of some fungi. ${ }^{17}$ It consists 




FIG. 1. Structure of chitosan. DA, degree of acetylation.

in a polysaccharide of two monomers units, D-glucosamine and $N$-acetyl-D-glucosamine, linked by a $\beta$ - $(1 \rightarrow 4)$-glycosidic bond (Fig. 1). The number of $N$-acetyl-D-glucosamine units in a chain corresponds to the degree of acetylation (DA), characteristic of the polymer. Chitosan is industrially prepared by the deacetylation of chitin in alkaline media. ${ }^{18-21}$ Chitin is a natural polysaccharide and one of the most abundant biopolymers on Earth, mainly present in the exoskeleton of arthropods and in the cell walls of many fungi. It is industrially extracted from crabs and shrimps, from fishing waste. Moreover, chitin and chitosan are nontoxic, biocompatible, and biodegradable. Chitosan is soluble in slightly acidic aqueous media. Chitosan is well-known to form films, as a result of the $\beta$-(1 $\rightarrow 4)$-glycosidic bond. ${ }^{18}$ High molar mass chitosan can form thin films which have been used in biomedical applications. ${ }^{18-21}$ Fernandez et al. ${ }^{22}$ and Park et al. ${ }^{23}$ have produced nanoscale features with chitosan thin films by soft or nanoimprint lithography for bioapplications (cell growth, cell interactions, biosensors, tissue engineering, etc.). Voznesenskiy et al. ${ }^{12,13}$ have studied chitosan and chitosan-metal nanofilms for the formation of submicron structures by e-beam lithography on glass substrates without transferring the features. Their results without transfer made them affirm that chitosan is not suitable as resist for microelectronics.

We aimed at demonstrating that chitosan is not only suitable for e-beam lithography but that it can also withstand $\mathrm{CHF}_{3}$ plasma etching step. Consequently, nanopatterns can be obtained with a high resolution into a silica substrate using organic solvent-free water-developable biosourced chitosan resist by a conventional e-beam lithography/etching process (Fig. 2).

\section{EXPERIMENT}

\section{A. Materials}

To circumvent the batch to batch variability, highly deacetylated chitosan was used. Chitosan was provided by Mahtani Chitosan Pvt., Ltd. (India), from squid pens and further purified according to the procedure of Rinaudo. ${ }^{18}$ Its molar mass of $570 \mathrm{~kg} \mathrm{~mol}^{-1}$ was measured by size exclusion chromatography. Chitosans of DA of 2\%,8\%, and 35\% were prepared. DA was quantified by ${ }^{1} \mathrm{H}$ NMR using an AVANCE III $400 \mathrm{MHz}$ spectrometer. Deionized water (ultrapure, $18 \mathrm{M} \Omega$ ) and acetic acid (Fluka Analytical, glacial acetic acid) were used to prepare chitosan solutions and developers. Chitosan films were deposited on silicon substrates with a 90 nm-thick hardmask layer of PECVD-deposited silica.

\section{B. Methods for chitosan film preparation and characterizations}

Solid chitosan was dissolved overnight at concentration of $0.7 \%(\mathrm{w} / \mathrm{v})$ in acetic acid deionized water solution. Acetic acid was stoichiometrically added with respect to the free amine of the glucosamine residues. Chitosan films were prepared by spin-coating at $5000 \mathrm{radmin}^{-1}$ and $3000 \mathrm{rad} \mathrm{s}^{-2}$ for $30 \mathrm{~s}$ followed by a softbake at $100{ }^{\circ} \mathrm{C}$ for $1 \mathrm{~min}$ on hotplate on silica/silicon substrates. It is well known that chitosan through hydrogen bonds have a strong adhesion on silica and silicon surfaces, thanks to $\mathrm{SiOH}$ groups. ${ }^{24}$

Film thickness was measured by ellipsometry with a spectroscopic ellipsometer UVISEL ${ }^{\mathrm{TM}}$ from Horiba using the classical formula dispersion as model in the Horiba software adapted to chitosan by adjusting the refractive index between 1.5 and 1.6 and the extinction coefficient to 0 for $630 \mathrm{~nm} .^{25}$

Thermal stability of chitosan films was assessed by temperature program desorption-mass spectroscopy (TPD-MS) with a heating rate of $5^{\circ} \mathrm{C} \mathrm{min}{ }^{-1}$ at $10^{-3} \mathrm{~Pa}$ in pressure. Positive ions generated by electron impact with an energy of $70 \mathrm{eV}$ on desorbed products were collected by a quadripole and analyzed by a MX7304 A Selmi mass spectroscopy device.

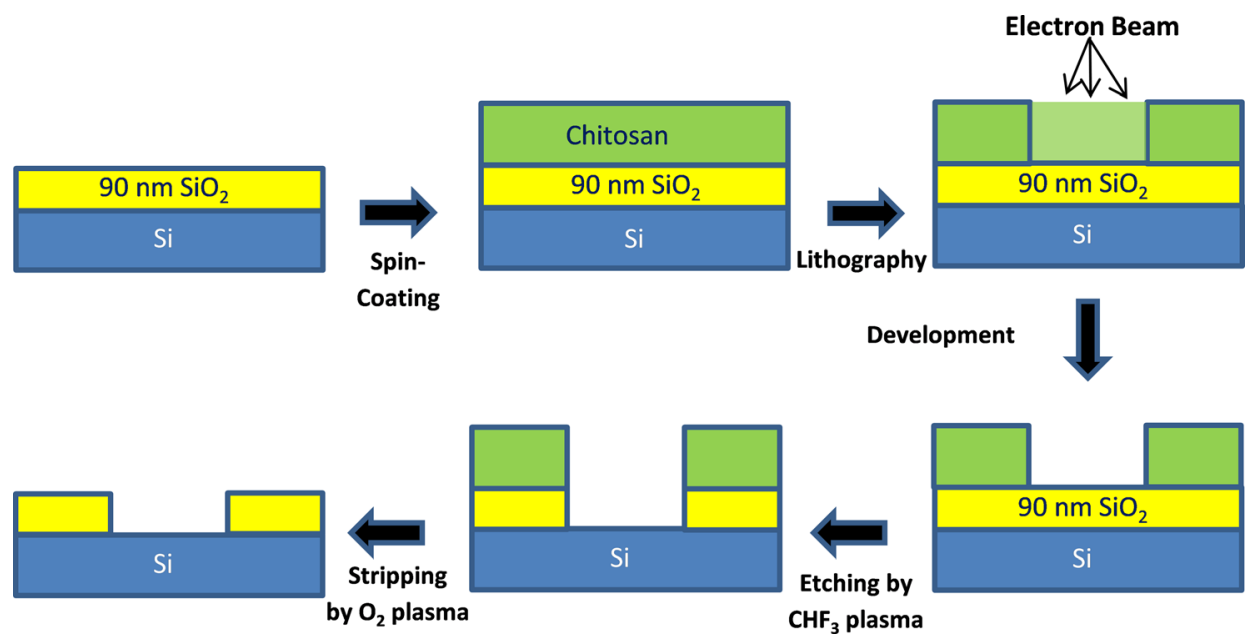

FIG. 2. (Color online) Scheme of the applied lithography-etching process. 


\section{E-beam lithography and etching process}

E-beam lithography was performed on a RAITH Elphy Quantum modified scanning electron microscope (SEM, FEI Inspect F) at $30 \mathrm{kV}$ and $10 \mathrm{pA}$ for a working distance at $6.9 \mathrm{~mm}$.

Etching selectivity study of chitosan films was carried out in a reactive ion etcher (RIE) Corial $200 \mathrm{~S}$ using $\mathrm{CHF}_{3}$ gas reactant (usually used for silica etching) during $2 \mathrm{~min}$ under $100 \mathrm{sccm}$ of $\mathrm{CHF}_{3}$ at a pressure of $50 \mathrm{mTorr}$ at $20^{\circ} \mathrm{C}$ for a power of $140 \mathrm{~W}$ (corresponding to a bias voltage of $590 \mathrm{~V}$ ). Chitosan was, then, selectively removed by $\mathrm{O}_{2}$ plasma for $1 \mathrm{~min}$ under $100 \mathrm{sccm}$ of $\mathrm{O}_{2}$ at $100 \mathrm{mTorr}, 20^{\circ} \mathrm{C}, 100 \mathrm{~W}$, and bias voltage of $460 \mathrm{~V}$.

\section{Features characterizations}

Feature observations were realized by SEM on a scanning electron microscope JEOL JSM $7401 \mathrm{~F}$ at $2 \mathrm{kV}, 5 \mu \mathrm{A}$, and a working distance of $4 \mathrm{~mm}$. The IMAGE J software was used for the analysis of the SEM images to measure the size of the features.

The depth of the features was measured with a profilometer Alpha-Step ${ }^{\circledR} 500$ Surface Profiler from KLA Tencor.

\section{RESULTS AND DISCUSSION}

\section{A. Thermal stability of the film}

Spin-coating is generally followed by a softbake to remove the solvent staying in the film. For chitosan films, the softbake is at $100^{\circ} \mathrm{C}$ during $1 \mathrm{~min}$ in order to be compatible with standard microelectronic technology. We checked by TPD-MS if this step does not generate the thermal degradation of chitosan.

The TPD-MS spectrum in Fig. 3 shows a similar behavior of the solid chitosan than in thin film. From 30 to $250^{\circ} \mathrm{C}$, desorption of residual water $(\mathrm{m} / \mathrm{z}=18$, with fragments at $\mathrm{m} / \mathrm{z}$ $=17$ ) and desorption and degradation of $\mathrm{CO}$ or $\mathrm{CO}_{2}$ contaminants $(m / z=28$ and 44$)$ occur. From 250 to $375^{\circ} \mathrm{C}$, several products are generated by thermal degradation, particularly water $(m / z=18)$, ammonia $(m / z=17)$, and carbon monoxide $(m / z=28)$. Other products are fragments of heterocycles.

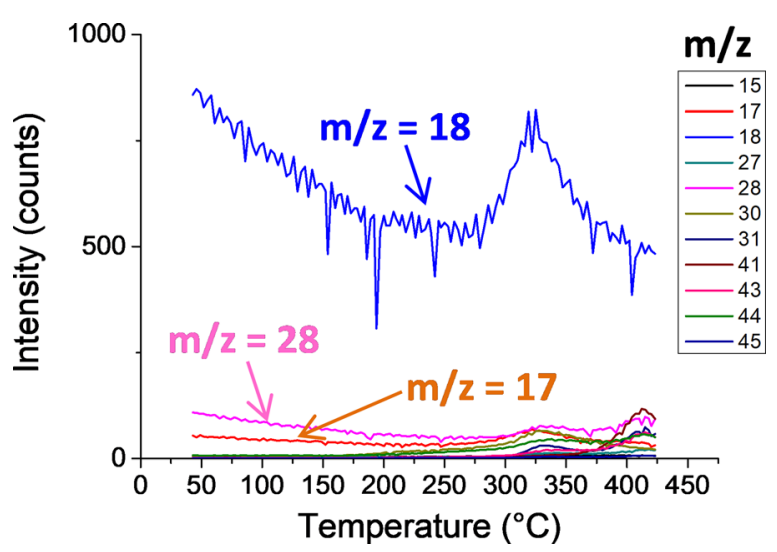

FIG. 3. (Color online) TPD-MS spectrum of a film of chitosan of DA $2 \%$ after spin-coating and after a softbake at $100^{\circ} \mathrm{C}$ during $1 \mathrm{~min}$. Each curve represents a ratio $\mathrm{m} / \mathrm{z}$.
From $400{ }^{\circ} \mathrm{C}$, we can clearly see the beginning of a second step of thermal degradation. Our observations are in accordance with those of Corazzari et al. ${ }^{26}$ who have studied the thermal degradation of chitosan powder. They observed that degradation occurred in two steps. A first step between 250 and $350^{\circ} \mathrm{C}$ generated mainly water, ammonia, carbon monoxide, and carbon dioxide. The second step took place between 450 and $750{ }^{\circ} \mathrm{C}$ with the formation of methane and a graphite-like product. During these two steps, water and several heterocycles as pyrazine, pyridine were generated by the breaking of the glycosidic bond.

Therefore, the thermal stability of chitosan thin films is similar to the one of chitosan powder allowing for a softbake at $100^{\circ} \mathrm{C}$ without degradation of the chitosan films.

In addition, we can see that the film does not contain acetic acid after spin-coating and softbake given that any product with $\mathrm{m} / \mathrm{z}=45$, characteristic of acetic acid, is generated during the desorption step from 30 to $250^{\circ} \mathrm{C}$.

\section{B. Assessment of an appropriate developer}

In order to choose an appropriate developer, the stability of the film was studied by measuring the film thickness by ellipsometry before and after immersion in deionized water, $0.5 \%, 1 \%$, and 5\% acetic acid solutions (Fig. 4). From the difference between these two thicknesses for the time of immersion, we could calculate the dissolution rate of chitosan films for each solvent. In acetic acid solutions, the dissolution rate was above $6 \mathrm{~nm} \mathrm{~s}^{-1}$ for all tested chitosan. On the contrary, in water, the chitosan films remain intact even after $90 \mathrm{~s}$ immersion duration. This is consistent with the fact that deionized water is not a solvent of chitosan because its $p \mathrm{H}$ is not acidic enough $(p \mathrm{H}>6)$. However, it seems that for DA $35 \%$ the dissolution rate was not zero.

However, exposed area may be soluble in water. Indeed, according to Gryczka et al., ${ }^{27}$ e-beam would generate the break of the glycosidic bond between units without affecting the amino groups leading to a decrease in molecular weight. Choi et $a l^{28}$ demonstrated that chitosan degraded by gamma irradiation has a better solubility in water. In addition, the

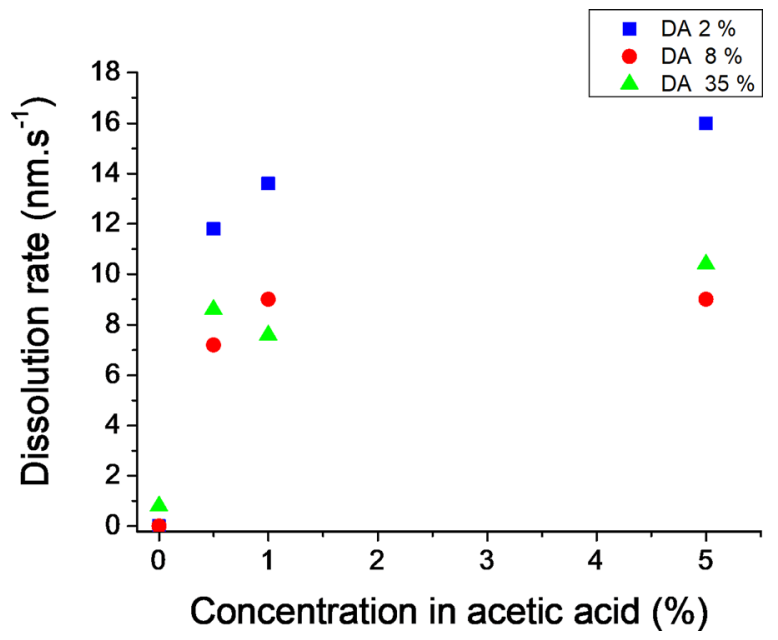

Fig. 4. (Color online) Dissolution rate after immersion of $100 \mathrm{~nm}$-thick chitosan films for different DA in deionized water and in acetic acid solutions. 
D-glucosamine monomer of chitosan has a pKa of $7.9,{ }^{29}$ higher than chitosan pKa [6.0 (Ref. 18)]. During the development in water, we can expect that deionized water will dissolve the shortened chains whose pKa should be between 6.0 and 7.9. So, deionized water was chosen as our developer in order to maximize the difference in solubility between the chitosan degraded by the e-beam exposition and the nonexposed chitosan.

\section{Selectivity}

For the transfer of features into silica by $\mathrm{CHF}_{3}$ plasma etching, chitosans selectivity was assessed. The selectivity of PMMA (950 PMMA A4, Microchem) films (70 nm) under our plasma etching conditions was used as a reference.

Figure 5 displays the selectivity of chitosan for three DA in comparison with PMMA. The selectivity was calculated as follows. Chitosan film and silica layer thicknesses were measured by ellipsometry before plasma etching. Etching was performed on samples made of a substrate of silicon with a chitosan film $(90 \mathrm{~nm})$ on a silica layer $(200 \mathrm{~nm})$. Etching was followed by laser interferometry giving the time of etching for each layer. From the time of etching and the layer thickness, etching rate is calculated for chitosan and silica. Selectivity corresponds to the ratio between silica etching rate and chitosan etching rate. For these three DA, chitosan had a slightly higher selectivity (4.35 for DA 2\%) compared to PMMA measured at 4.20.

\section{Chitosan electrosensitivity}

Chitosan electrosensitivity was studied on $99 \mathrm{~nm} \pm 7 \mathrm{~nm}$ thick chitosan (RMS $3 \mathrm{~nm}$ ) with DA $2 \%$ films by applying a dose screening from 20 to $1000 \mu \mathrm{C} \mathrm{cm}^{-2}$. Test patterns were $5 \times 5 \mu \mathrm{m}^{2}$ squares. The dose effect on pattern depth for different times of deionized water development $(5,25$, and 60 s) is shown in Fig. 6.

Whatever the water development time, features started to be revealed at a minimum dose of $40 \mu \mathrm{C} \mathrm{cm}^{-2}$. Above $160 \mu \mathrm{C} \mathrm{cm}^{-2}$, the exposed chitosan resist was completely dissolved allowing to reach the silica layer. From these

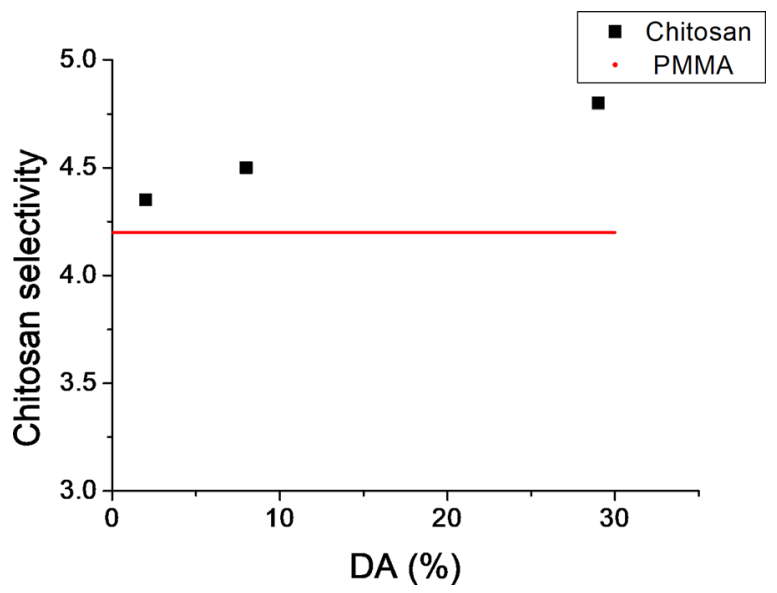

FIG. 5. (Color online) Selectivity of chitosan compared to PMMA for 2\%, 8\% and 35\% DA for $\mathrm{CHF}_{3}$ plasma. Dashed line corresponds to PMMA selectivity. Chitosan and PMMA were filmed on $200 \mathrm{~nm}$ thick PECVDdeposited $\mathrm{SiO}_{2}$. Chitosan (or PMMA) selectivity corresponds to the ratio of $\mathrm{SiO}_{2}$ etching rate on chitosan (or PMMA) etching rate.

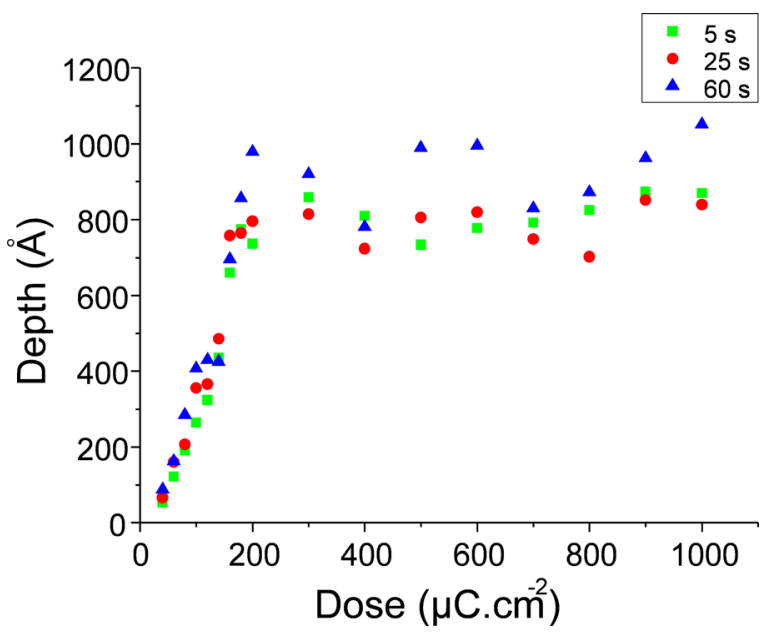

FIG. 6. (Color online) Effect of dose on the depth of the patterns for $100 \mathrm{~nm}$ thick resists developed in deionized water for 5,25 , and $60 \mathrm{~s}$.

results, we can estimate the e-beam degraded chitosan dissolution rate. It corresponds to the ratio of the depth on the time of development. For $5 \mathrm{~s}$ of development, from around $160 \mu \mathrm{C} \mathrm{cm}^{-2}$, the dissolution rate of e-beam degraded chitosan is of $16 \mathrm{~nm} \mathrm{~s}^{-1}$ in deionized water at room temperature. We can note that the depth of development depends only on the dose. The low dependence on the developing time is useful in fabrication of multilevel structures.

The deviation of the developed features from the expected $5 \mu \mathrm{m}$ squares as a function of the dose is given in Fig. 7. It was obtained by comparing the squares' size measured from SEM images and the expected $5 \mu \mathrm{m}$ size. We note that oversizing of the patterns occurred for doses above $200 \mu \mathrm{C} \mathrm{cm}^{-2}$. For lower doses, the obtained size deviated by less than $3.6 \%$. Underexposure was obtained for doses lower than $100 \mu \mathrm{C} \mathrm{cm}^{-2}$. Between 300 and $700 \mu \mathrm{C} \mathrm{cm}^{-2}$, the size deviation ranged from $11.6 \%$ to $18.4 \%$. Above $800 \mu \mathrm{C} \mathrm{cm}^{-2}$, the chitosan film was clearly overexposed, proximity effects were significant and generated an enlargement of the size by a factor of 2. Taking into account the size and depth of the obtained features, the best range of doses was comprised

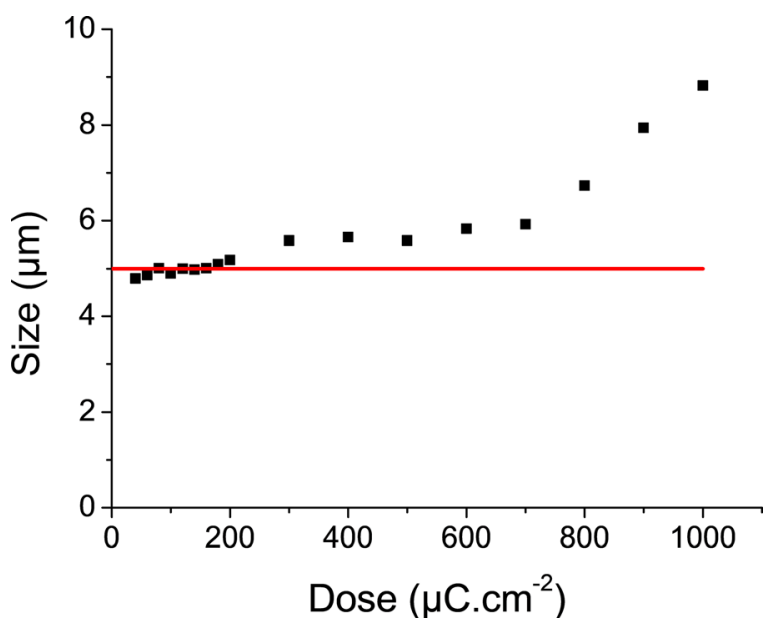

FIG. 7. (Color online) Effect of the dose on the size of a pattern of $5 \mu \mathrm{m}$. Red line corresponds to the aim of $5 \mu \mathrm{m}$ in size. 
between 160 and $300 \mu \mathrm{C} \mathrm{cm}^{-2}$ with an optimal dose around $200 \mu \mathrm{C} \mathrm{cm}^{-2}$.

\section{E. Resolution}

On the basis of these results, we increased the resolution until patterning lines of $50 \mathrm{~nm}$ spaced by 500,300, and $100 \mathrm{~nm}$. Scanning electronic microscopy (SEM) top views of
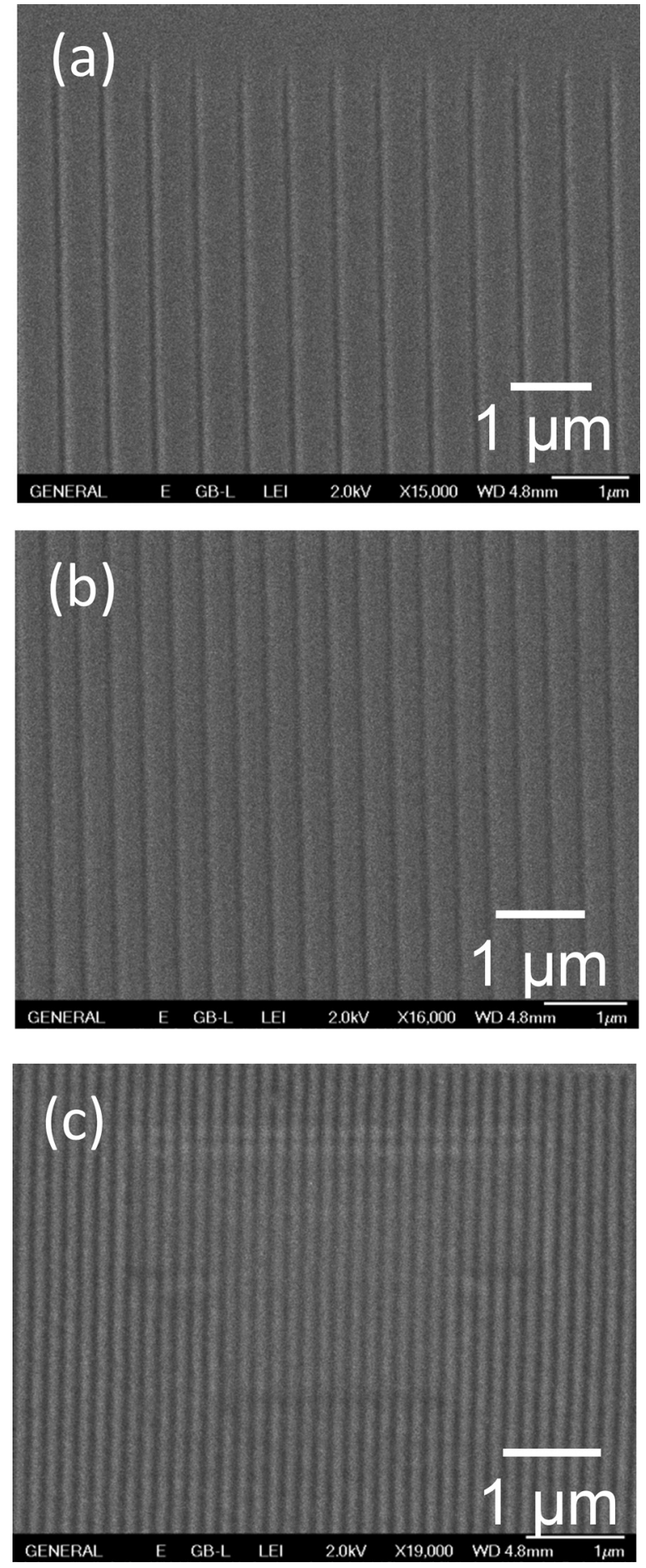

FIG. 8. SEM images of nanopatterns obtained by EB lithography at $30 \mathrm{kV}$ and $10 \mathrm{pA}$ in a chitosan positive resist at an optimal dose range between 180 and $220 \mu \mathrm{Ccm}^{-2}$. Average feature sizes on 50 measures are (a) $65 \mathrm{~nm}$ line and $505 \mathrm{~nm}$ space, (b) $70 \mathrm{~nm}$ line and $288 \mathrm{~nm}$ space, and (c) $59 \mathrm{~nm}$ line and $97 \mathrm{~nm}$ space.

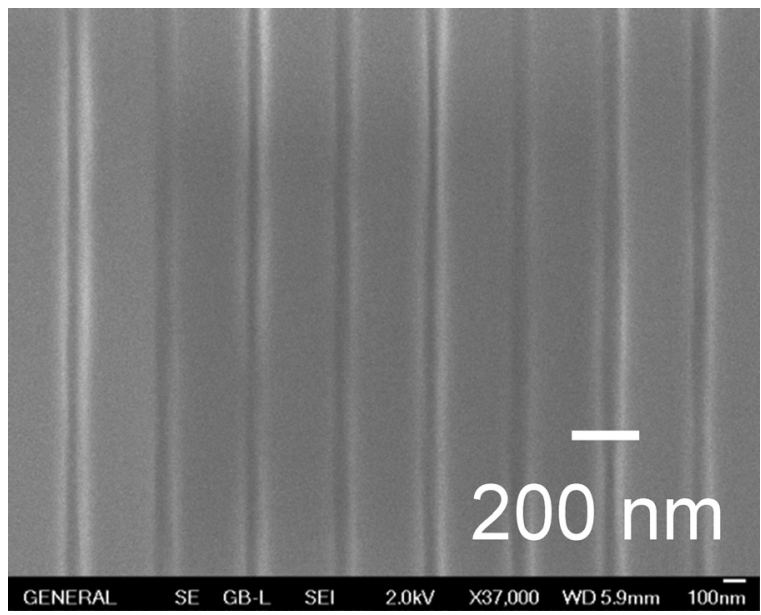

FIG. 9. SEM image of patterns obtained by EB lithography at $180 \mu \mathrm{C} \mathrm{cm}^{-2}$ on chitosan after transfer by $\mathrm{CHF}_{3}$ plasma etching and stripping of chitosan $47 \mathrm{~nm}$ line and $332 \mathrm{~nm}$ space on the average of 50 measures.

chitosan DA 2\% films after $30 \mathrm{~s}$ of deionized water developments are displayed in Fig. 8.

As displayed on the SEM images of Fig. 8, lines with a width near $50 \mathrm{~nm}$ for different spacings could be written in a chitosan film as positive resist. According to SEM images, features are well defined for high resolution without applying any proximity effect correction during exposure.

A $50 \mathrm{~nm}$ lines spaced of $300 \mathrm{~nm}$ pattern of chitosan was transferred in $\mathrm{SiO}_{2}$ hardmask layer by a RIE plasma etching of $\mathrm{CHF}_{3}$ followed by the selective removal by $\mathrm{O}_{2}$ plasma of the chitosan layer.

The SEM image in Fig. 9 shows the patterns after transfer and stripping of the resist. The size is well respected for $50 \mathrm{~nm}$ lines spaced of $300 \mathrm{~nm}$ for the lines. We can note that, even after RIE, the features dimensions were of the same order. RIE did not modify significantly feature dimensions and enables a transfer of high quality. In addition, feature dimensions on chitosan resists appear reproducible.

\section{SUMMARY AND CONCLUSIONS}

In summary, we demonstrated chitosan film is a biosourced, chemically unmodified, water-developable, positive tone, and plasma resistant resist for a complete green e-beam lithography/etching process. No hazardous or ecotoxic chemicals (resins, solvents, and developers) were required during the process nor during the resist lifetime cycle. Indeed, chitosan, a natural polysaccharide prepared from fishing waste, can be chosen as a positive e-beam resist with success, thanks to its $p \mathrm{H}$-dependent solubility in aqueous solutions and its resistance to etching. For doses between 160 and $300 \mu \mathrm{C} \mathrm{cm}^{-2}$ with an optimal dose around $200 \mu \mathrm{Ccm}^{-2}$, a complete process of e-beam lithography and plasma transfer in $\mathrm{SiO}_{2}$ layer was achieved with high resolution, $50 \mathrm{~nm}$ line patterns are well defined, with respected dimensions and few line edge roughness given that the resolution limit of the lithography device. Future development will focuse on the development of a negative tone chitosan resist. 


\section{ACKNOWLEDGMENTS}

The authors would like to thank the Nanolyon Platform for equipment and supports. They also thank the NMR Polymer Center of Institut de Chimie de Lyon (No. FR5223) for assistance and access to the NMR facilities. Pulsalys is acknowledged for financial support. Mathieu Caillau is affiliated to the doctoral contract from Electronic, Electrotechnic, and Automatic doctoral School.

1"Executive summary," in International Technology Roadmap for Semiconductors, 2011 ed., available at https://www.semiconductors.org/ clientuploads/Research_Technology/ITRS/2011/2011ExecSum.pdf.

${ }^{2}$ I. Haller, M. Hatzakis, and R. Srinivasan, IBM J. Res. Dev. 12, 251 (1968).

${ }^{3}$ MicroChem., PMMA Data Sheet Microchem (MicroChem Corp., Newton, MA, 2001).

${ }^{4}$ G. H. Bernstein, D. A. Hill, and W. P. Liu, J. Appl. Phys. 71, 4066 (1992).

${ }^{5} \mathrm{H}$. Fiege et al., in Ullmann's Encyclopedia of Industrial Chemistry, edited by B. Elvers (Wiley-VCH, Weinheim, 2005), pp. 13972-14012.

${ }^{6}$ L. M. Gandía and M. Montes, Appl. Catal. A 101, L1 (1993).

${ }^{7}$ K. Weissermel and H.-J. Arpe, Industrial Organic Chemistry, 4th ed. (Wiley-VCH, Weinheim, 2003).

${ }^{8}$ S. Takei, A. Oshima, A. Sekiguchi, N. Yanamori, M. Kashiwakura, T. Kozawa, and S. Tagawa, Appl. Phys. Express 4, 106502 (2011).

${ }^{9}$ S. Takei, A. Oshima, T. Wakabayashi, T. Kozawa, and S. Tagawa, Appl. Phys. Lett. 101, 033106 (2012).

${ }^{10} \mathrm{~S}$. Takei et al., Microelectron. Eng. 122, 70 (2014).

${ }^{11}$ S. Kim, B. Marelli, M. A. Brenckle, A. N. Mitropoulos, E.-S. Gil, K. Tsioris, H. Tao, D. L. Kaplan, and F. G. Omenetto, Nat. Nanotechnol. 9, 306 (2014).

${ }^{12}$ S. Voznesenskiy, A. Nepomnyaschiy, and Y. Kulchin, Solid State Phenom. 213, 180 (2014).
${ }^{13}$ S. Voznesenskiy and A. Nepomnyaschiy, Solid State Phenom. 245, 195 (2015).

${ }^{14}$ J. Park, S.-G. Lee, B. Marelli, M. Lee, T. Kim, H.-K. Oh, H. Jeon, F. G. Omenetto, and S. Kim, RSC Adv. 6, 39330 (2016).

${ }^{15}$ K. Maximova, X. Wang, A. Balčytis, L. Fan, J. Li, and S. Juodkazis, Biomicrofluidics 10, 54101 (2016).

${ }^{16}$ S. Takei, A. Oshima, T. G. Oyama, K. Ito, K. Sugahara, M. Kashiwakura, T. Kozawa, S. Tagawa, and M. Hanabata, Jpn. J. Appl. Phys. 53, 116505 (2014).

${ }^{17}$ A. Einbu and K. M. Vårum, Chemical Functional Properties of Food Saccharides, edited by P. Tomasik (CRC, Boca Raton, FL, 2004), pp. 219-232.

${ }^{18}$ M. Rinaudo, Prog. Polym. Sci. 31, 603 (2006).

${ }^{19}$ I. Aranaz, M. Mengíbar, R. Harris, I. Paños, B. Miralles, N. Acosta, G. Galed, and Á. Heras, Curr. Chem. Biol. 3, 203 (2009).

${ }^{20}$ M. Dash, F. Chiellini, R. M. Ottenbrite, and E. Chiellini, Prog. Polym. Sci. 36, 981 (2011).

${ }^{21}$ M. N. Ravi Kumar, React. Funct. Polym. 46, 1 (2000).

${ }^{22}$ J. G. Fernandez, C. A. Mills, E. Martinez, M. J. Lopez-Bosque, X. Sisquella, A. Errachid, and J. Samitier, J. Biomed. Mater. Res., Part A 85, 242 (2008).

${ }^{23}$ I. Park, J. Cheng, A. P. Pisano, E. S. Lee, and J. H. Jeong, Appl. Phys. Lett. 90, 093902 (2007).

${ }^{24}$ J. S. Laskowski, Q. Liu, and C. T. O’Connor, Int. J. Miner. Process. 84, 59 (2007).

${ }^{25}$ W. H. Nosal, D. W. Thompson, L. Yan, S. Sarkar, A. Subramanian, and J. A. Woollam, Colloids Surf. B 43, 131 (2005).

${ }^{26}$ I. Corazzari, R. Nisticò, F. Turci, M. G. Faga, F. Franzoso, S. Tabasso, and G. Magnacca, Polym. Degrad. Stab. 112, 1 (2015).

${ }^{27}$ U. Gryczka, D. Dondi, A. G. Chmielewski, W. Migdal, A. Buttafava, and A. Faucitano, Radiat. Phys. Chem. 78, 543 (2009).

${ }^{28}$ W.-S. Choi, K. J. Ahn, D.-W. Lee, M.-W. Byun, and H.-J. Park, Polym. Degrad. Stab. 78, 533 (2002).

${ }^{29}$ A. Blaskó, C. A. Bunton, S. Bunel, C. Ibarra, and E. Moraga, Carbohydrate Res. 298, 163 (1997). 